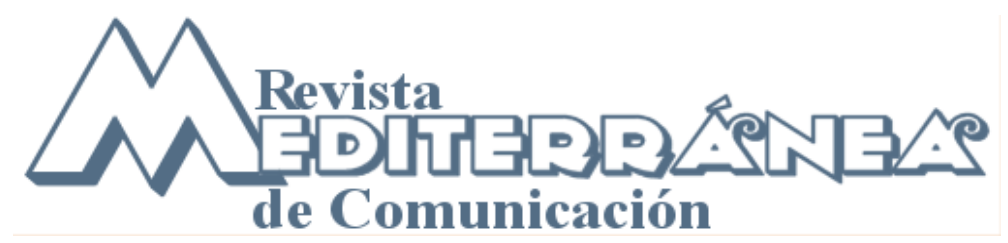

\title{
Mejorar la información: uso del lenguaje publicitario en las noticias audiovisuales.
}

\section{Improving information: using the language of advertising in the audiovisual news}

\author{
Dra. Elena Bandrés Goldáraz \\ Profesora Asociada de Producción de Informativos en TV. \\ Universidad de Zaragoza. Facultad de Filosofía y Letras. \\ bandres@unizar.es
}

\begin{abstract}
Resumen
La televisión es el medio preferido por el 89\% del público español para obtener información, pero el nivel de compresión y de recuerdo de las noticias escuchadas queda en entredicho, ya que los espectadores sólo recuerdan uno de cada tres datos emitidos en condiciones ideales de percepción. Con el fin de mejorar el grado de percepción de las noticias, proponemos aplicar algunas de las técnicas del lenguaje publicitario a la redacción de aquel género informativo.
\end{abstract}

Estas técnicas complementarían las ya utilizadas para la redacción de noticias que, según se desprende del grado de percepción demostrado por el público espectador, pueden ser insuficientes para la retención y comprensión de la información. Somos conscientes de que unir la creación publicitaria a la creación periodística en televisión puede convertirse en una estrategia peligrosa. Acotando bien cada campo, pretendemos mejorar el lenguaje informativo en un medio que, a pesar de que se ha desarrollado técnicamente de forma vertiginosa, en lo relativo al lenguaje utilizado, sin embargo, dicha evolución, a nuestro juicio, está por llegar. Para ello analizamos la técnica publicitaria en cuanto a la creación del mensaje y su eficacia y demostramos que existen campos compartidos entre la publicidad y la creación de noticias en televisión.

\section{Palabras clave}

Televisión; información; compresión; percepción; lenguaje; publicidad; España.

\section{Abstract}

Television is the preferred way of communication of $89 \%$ of the Spanish population but the level of compression and intake of the news heard is compromised by knowing that viewers only remember one out of three data issued in ideal conditions of viewing. To 
improve the level of perception of the news we suggest applying some of the advertising language techniques to the writing of this kind of information. These techniques are an addition to those already used for the newsroom because, according to the degree of awareness shown by the audience, they might be insufficient for remembering and understanding communication. We are well aware that using advertising bases for television journalism can be a dangerous strategy. By fixing the limits of each field, we aim to improve the news in a way, although technically it has developed at a breathtaking pace as far as language is concerned, that development is, according to us, still to come. For this reason we study this advertising technique about the creation of the message and its effectiveness and we show that there are shared fields between advertising and the creation of TV news.

\section{Keywords}

Television; information; understanding; perception; language; advertising; Spain.

Sumario: 1. Introducción. 2. Estado de la cuestión. 3. Preguntas de investigación. 4. Método. 5. Los campos compartidos del lenguaje publicitario y el lenguaje informativo. 6 . Técnicas del lenguaje publicitario aplicadas a las noticias. 7. El uso del lenguaje audiovisual en los mensajes informativos. 7.1 Planos, transiciones. 7.2 Integración del texto. 7.3 Elipsis. 7.4 Música. 8. Conclusiones. 9. Referencias bibliográficas. 10. Referencias en la red. 11. Notas.

Summary: 1. Introduction. 2. Current facts. 3. Research Questions. 4. Method 5. Shared fields between the advertising and the news language information. 6 . Techniques of the advertising language applied to the news. 7. The use of audiovisual language in informational messages. 7.1 Shots, transitions. 7.2 Integration of the text. 7.3 Ellipsis. 7.4 Music. 8. Conclusions. 9. Bibliography. 10. Internet links 11. Notes.

\section{Introducción}

Según el Anuario de Audiencia de Televisión, en 2008 los españoles aumentaron el consumo de televisión en cinco minutos diarios, hasta llegar a los 227 . Este tiempo ha ido aumentando en los últimos años según el Estudio General de Medios, que asegura que el público español dedicó a ver televisión, en 1998, una media diaria de 210 minutos. Este consumo subió a los 225 minutos en el año 2001.

En ese año, el 89,3\% de la población veía todos los días la televisión, frente al 36\% que leía diariamente la prensa o el 53\% que escuchaba diariamente la radio. El estudio señalaba a las mujeres, a los jóvenes menores de 20 años y a las personas mayores de 65 , como los principales consumidores de televisión; un pasatiempo que tenía a las clases medias y bajas como sus principales seguidores, que centraban sus preferencias en el fútbol y en los espacios informativos. En 2009, el perfil de la audiencia no varió 
sustancialmente, aunque se observó una ligera disminución en los espectadores de televisión, que se situaban en el $89 \%$. Aumentó el número de lectores de prensa al $39,8 \%$ y el de oyentes de radio al $55,3 \%$, mientras que el número de personas que se conectan a Internet era del 34,3\%.

En principio cabe pensar que, dado que la televisión lleva tantos años existiendo [1] el espectador debería haberse acostumbrado a un lenguaje y a una narrativa audiovisual específica. Pero esto no es así, ya que la televisión no ofrece el mismo código audiovisual de hace décadas. En este tiempo se ha pasado de ofrecer boletines hablados, prácticamente sin imágenes, a la utilización de ritmos trepidantes, conseguidos a base de planos excesivamente cortos de duración, con movimientos vertiginosos y llenos de color, acompañados por una música pegadiza. Los textos también se caracterizan por su brevedad en forma de eslóganes; frases que intentan resumir vastos pensamientos y en las que se cuelan tópicos y estereotipos. Lo espectacular, la acción rápida, el movimiento o el ritmo acelerado de las imágenes, se han convertido en el nuevo vocabulario audiovisual de los telespectadores. Este conjunto de elementos ha entrado a formar parte de las herramientas que el espectador necesita para descifrar y entender lo que está viendo. $Y$ de este nuevo lenguaje, utilizado también en la publicidad, en las promociones de cada cadena de televisión o en los nuevos programas de ficción y entretenimiento, se han contagiado también los espacios informativos. El problema surge al comprobar, como refiere Sánchez Corral (2003) que:

"la imagen carece de sintaxis, al menos carece de la sintaxis compleja que se requiere para elaborar el pensamiento superior y abstracto. La imagen ilustra, transmite (o sugiere) representaciones sensoriales; llega a describir, en el mejor de los casos; pero carece de poder argumentativo".

Nos encontramos, por tanto, en una situación en la que, a pesar de que la vorágine visual ha calado en los informativos, éstos no han adaptado la evolución de la imagen a su propia idiosincrasia, a su forma de expresión y a su propia finalidad.

\section{Estado de la cuestión}

En unos pocos años, las noticias han pasado de ser el texto en el que se contaba una información sin apenas datos visuales, a convertirse en un vehículo más en la presentación de imágenes grabadas y editadas como espectáculo. Los informativos no han podido escapar de esta tendencia, debido, también en parte, a su lucha por conseguir mayores audiencias y a su incómoda posición dentro de la parrilla en la que van programados. Posición difícil porque, tanto los programas que anteceden como los que siguen a un informativo, son espacios encaminados a entretener a la audiencia. De esta manera, y salvo honrosas excepciones, todo lo que se emite por televisión lleva impregnado en sus planos el sello del espectáculo. Este es un tema ya profusamente tratado. Así lo afirma González Requena (1987: 77), cuando dice que: "el espectáculo televisivo es precisamente un espejo puesto ante otro espejo, un espejo doble que se 
remite infinitamente hacia sí mismo. Y al hacerlo, fagocita la realidad, la captura en su interior, convirtiéndola en espectáculo".

Del Rey Morato (1998: 38) también asegura que la televisión, en su faceta informativa, es "máquina productora de espectáculo" o lo que se conoce desde la década de 1980 como infotainment tal y como asegura Bertrand en Martínez Albertos (1999: 5)

"la info-diversión, o sea, hechos diversos, escándalos, conflictos, desastres; es decir, espectáculos, interesantes ciertamente, llenos de personajes pintorescos que a menudo carecen de importancia, que informan muy poco sobre el mundo que nos rodea".

Por lo tanto, la información en televisión sigue condicionada por la nueva naturaleza del medio, en el que todo está dirigido a divertir y entretener; de ahí que un noticiario, como ya es harto conocido, esté concebido como "un formato para el entretenimiento, no para la educación, la reflexión o la catarsis” (Postman, 1991: 91). Por eso, en los informativos de televisión, los asuntos importantes rara vez son explicados con el tiempo y la profundidad necesarios para que el espectador pueda comprender su alcance e implicaciones, salvo que se piense que con noticias de menos de dos minutos de duración pueda explicarse con profundidad una información. Esta es la media que dedican, las cadenas generalistas que hay en España, a las noticias incluidas en sus informativos, según un estudio de diversas universidades españolas (2006), aunque las televisiones intentan contextualizar las informaciones de mayor calado ofreciendo noticias complementarias a la información principal. Tal y como recoge dicho informe, las televisiones prefieren suministrar agilidad frente a profundidad. En cuanto a la selección de los temas que se tratan en los informativos, forman parte de la agenda los deportes y los desastres frente a los asuntos políticos y a los de interés general.

La televisión actual constituye una creciente mezcla de géneros y formatos, de ficción e información con el denominador común del ya mencionado entretenimiento, tal y como subrayan Zilman y Vorderer (2000: 23-29). Los informativos se hallan inmersos en esta cultura neotelevisiva que se asemeja a un mosaico. De esta manera, tal y como afirma Cortés (1999: 51), "la oferta neotelevisiva se convierte en un gran supermercado, donde la ficción, la información, el espectáculo y la publicidad forman parte de un totum revolutum, en el que a veces, la distinción de estos campos es casi imperceptible".

Dentro de este panorama del show bussines integral televisivo, la información se ha hecho víctima de un sistema que no logra sus objetivos de informar y de hacer permanecer sus contenidos en la memoria del espectador, más allá de los segundos que se tarda en pasar a la noticia siguiente. Los estudios clásicos, y casi únicos, de hace unos años sobre el grado de percepción de las noticias televisivas afirman que, en Estados Unidos, los telespectadores son incapaces de precisar más del $2,5 \%$ de los contenidos tratados en el informativo. Sólo se retienen acontecimientos excepcionales y temas que les conciernen directamente. El 51\% no recuerda ni una sola información del informativo recién visto (Fombona: 1997: 33). En España, el estudio de Orive (1988) sobre la recepción de los informativos asegura que el espectador sólo recuerda uno de cada tres datos emitidos en condiciones ideales de percepción. En cuanto se dan 
situaciones que distraen la atención del espectador en el momento de ver las noticias en televisión, esta asimilación y retención se reducen notablemente.

Según los últimos estudios realizados sobre el nivel de consumo de los informativos de televisión en España, el índice de confianza que tienen los espectadores respecto a las noticias que dan las distintas cadenas de televisión ha descendido sustancialmente. En el barómetro de opinión del año 2000, elaborado por el Centro de Investigaciones Sociológicas (CIS), al $58,4 \%$ de los encuestados los informativos les merecen "bastante confianza" y al $13,5 \%$ "mucha".

En 2003, el 6,7\% demuestra tener mucha confianza en estos programas; al $46,3 \%$ les sugieren bastante confianza mientras que para el 36,5 les inspiran poca confianza; para el 6,0 , ninguna y el 2,8 y 1,7 no sabe o no contesta. Estos últimos porcentajes se obtienen del $83 \%$ de la población que declara ver la televisión todos o casi todos los días. De este dato, el $71,5 \%$ ve diariamente los informativos, siendo el $75 \%$ varones y el $68 \%$ mujeres. El nivel de confianza en las noticias sigue aminorando si tenemos en cuenta un estudio de la Asociación de la Prensa de Madrid (2009: 11), en el que se asegura que la televisión sólo es el medio más creíble para el $32,8 \%$, porcentaje que no recupera el 33,3\% alcanzado en el 2006.

Y mientras desciende el nivel de confianza en las noticias de televisión, aumenta el porcentaje en el nivel de audiencia de los informativos. En el último Estudio General de Medios de 2009 , se asegura que el $88,5 \%$ ve la televisión todos los días y en el informe anual de la profesión periodística de 2009, elaborado por la Asociación de la Prensa de Madrid, se asegura que el $85,8 \%$ de los encuestados declara ver al menos un noticiario de televisión al día, frente al $83,1 \%$ de hace un año y al $79,1 \%$ de 2007 . La radio tiene un seguimiento como fuente informativa del $40,3 \%$ frente al $41,7 \%$ en 2008 y frente al $38,1 \%$ de 2007. El consumo de Internet, en este aspecto, se sitúa en el $25,2 \%$ frente al $18,5 \%$ en 2008 y frente al $15,2 \%$ de 2007 ; mientras que la tasa de lectores de prensa diaria sigue disminuyendo año tras año: del 46,5\% en 2008 se ha pasado al 43,6\% en 2009, frente al 50,6\% del 2007.

Por lo tanto, se da la paradoja de que, siendo los informativos televisivos los programas más demandados por la ciudadanía para obtener información del mundo que le rodea, el grado de confianza demostrada por los espectadores no se corresponde con el alto consumo, mientras que la percepción y el nivel de recuerdo de las informaciones resultan más bien escasos. Desconocemos la existencia de estudios (en el caso de que los haya) que justifiquen el motivo de esta falta de confianza, pero sí se han realizado profusas investigaciones sobre la dificultad que registran los espectadores para recordar y comprender las noticias de televisión. El espectador, lejos de obtener los parámetros y las claves de lo que ocurre a su alrededor, le resulta difícil almacenar datos en su memoria, ya que el trinomio imagen-palabra-sonido presenta serios problemas en el proceso cognitivo, así como en el establecimiento de causas y en las extracción de conclusiones de los contenidos informativos. Como explica Gunter (1997: 128), "la escasa retención de las noticias no es consecuencia automática de la falta de interés previo por parte de la audiencia sobre los temas que aparecen en el informativo". El 
cerebro receptor de la información experimenta un exceso de datos inconexos y descontextualizados que, lejos de establecer las bases para un conocimiento de la realidad, sólo contribuyen a introducir al espectador en un laberinto audiovisual del que resulta muy difícil fijar conocimientos y extraer conclusiones ciertas. $Y$ como asegura Pestano (2008):

"una de las cuestiones clave sería si existen signos en la práctica informativa que sirvan para diferenciar entre informaciones de calidad de las que no lo son. Lamentablemente, muchos de estos signos no son evidentes".

Sartori (1998) inició un profundo debate al señalar que la televisión ha transformando al homo sapiens en homo videns. ¿El hombre está perdiendo la capacidad de pensar cuando se encuentra frente a la televisión, tal y como defendió dicho filósofo? La producción de imágenes no asimiladas disminuye la actitud de abstracción, es decir, de pensar y en esto se basó este autor para argumentar que "la televisión produce imágenes y anula los conceptos y de este modo atrofia nuestra capacidad de abstracción y con ella toda nuestra capacidad de entender" (Sartori: 47).

Frente a la crítica devastadora del medio, en la que se instala también Bordieu como principal exponente, otros autores como Stephens (1998: 200) aseguran que no se puede deducir que la televisión anule la capacidad de abstracción. Y si consideramos la perspectiva de Pérez Tornero (1994: 90-92):

"La imagen televisiva no se presenta sólo con un golpe de intuición, se construye en la mente del receptor a partir de una sucesión temporal. Como el lenguaje hablado, se desarrolla en el tiempo, permitiendo, en consecuencia, el curso del pensamiento y la imagen (...). No se ve pasivamente, reclama, también por naturaleza, actividad cerebral, esfuerzo de construcción o de reconstrucción. Requiere complicidad activa del espectador y participación en el flujo de informaciones. Y lo hace a tal ritmo, con tal exigencia de dedicación y de atención que, eso sí, constituye una fuerza poderosa, casi hipnótica, tremendamente absorbente".

Esta discrepancia podría abrir, en principio, la posibilidad de iniciar un método que permitiera informar de forma más adecuada, entendiendo por ello el proceso para conseguir que el espectador no sólo asimile la información que recibe, sino que la retenga en su memoria con el fin de almacenar datos y claves (verídicas) con las que poder interpretar el mundo que le rodea.

El nivel de recuerdo de los informativos se ha estudiado desde los años setenta. Destacamos la línea de investigación cognitiva del recuerdo de noticias desarrollada por Gunter (1997), Berry (1980) y Clifford (1981) recogida por Badillo (1996). Robinson y Levy (1986) achacan a las limitaciones del medio la pobre comprensión y recuerdo del público, mientras que "Griffin (1992) plantea las bases del formato de presentación de las noticias televisivas como una combinación de símbolos visuales estandarizados", tal y como afirma Badillo (1996). En la investigación sobre las formas narrativas de las noticias de televisión, Charles Bantz y Akiba Cohen (1985) plantearon "tres puntos de vista fundamentales: el análisis de contenido, los trabajos de cognición, originados 
desde la tradición de la psicología y los trabajos de control centrados en los estudios organizativos" (Badillo, 1996).

Pero, además de estos campos de investigación, proponemos iniciar otro sobre el actual lenguaje audiovisual utilizado en los espacios informativos. Consideramos que no es percibido con nitidez por parte del público, debido a diferentes causas como pueden ser desde la rapidez en la locución, la incorrecta sintaxis del texto, la utilización de perífrasis y circunloquios que impiden una correcta descodificación por parte del telespectador, el uso desacertado de la imagen como elemento narrativo hasta el desacompasamiento de las imágenes con el texto que pretenden complementar.

No en vano, como señala Orive (1988: 249), "el lenguaje televisivo resulta el más complejo de todos los usados por los medios modernos, debido a la conjunción en una sola expresión del triángulo palabra-música-imagen", a lo que habría que añadir el sonido ambiente de cada plano utilizado y los recursos gráficos.

Consideramos que el papel del sonido ambiente puede estar íntimamente relacionado con las técnicas del overlapping, técnica definida como retraso del sonido respecto de la imagen, Morales (2008). El sonido ambiente, además de ayudar a ubicar la información y de ofrecer el sonido real que aporta la imagen puede también adelantar la información y con ello, atraer la atención del espectador, tal y como sugiere esta técnica que relata dicho autor:

"los cambios de intensidad sonora activan respuestas de orientación y defensa y se relacionan con el nivel de cambio y novedad de la información. La literatura sugiere que la impresión emocional de sorpresa se activa por cambios inesperados en nuestro entorno circundante Ohmann (1997). Esta evidencia empírica de los estudios psicofísicos puede ser trasladada al entorno de la experiencia audiovisual, tomando en cuenta que uno de los principales objetivos del discurso cinematográfico es generar estados emocionales intensos para dirigir la atención y facilitar la comprensión de los mensajes"

Volviendo a Orive (1988: 268), la consecuencia directa de la complejidad que aporta el trinomio mencionado es que "no se cumple la función de los noticiarios, al no ser captado el contenido último del mensaje transmitido". La desinformación que sufre el espectador se agrava, además, con las imágenes de archivo que se utilizan, sin especificar en pantalla que se hace uso de ellas. En muchas ocasiones, dichas imágenes se sacan de contexto y no explican cuál es el estado de la situación. Esta desinformación parcela en microespacios la representación de la realidad que intentan transmitir. Desaparecen las ideas por la imposibilidad de utilizar imágenes específicas y es entonces cuando se hace prevalecer lo impactante frente a lo informativo. En ese momento, el periodismo desaparece para dar paso al espectáculo. Como asegura Diezhandino (1994: 21), "reduciendo lo actual a lo instantáneo, y lo instantáneo a lo resonante" Varios años antes, Pierre Bordieu (1997: 40) ya se preguntaba si el espectador dispone del código necesario para descodificar y entender lo que la noticia 


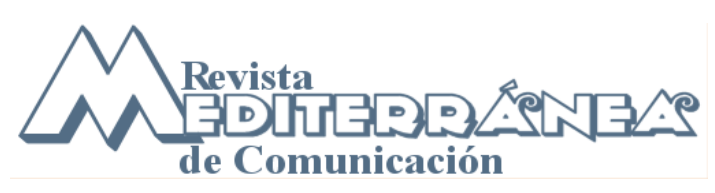

ISSN 1989-872X - Año 1(2010), pp. 173-194

en televisión le está transmitiendo. Según este crítico, la recepción óptima de la noticia sólo se produce cuando los periodistas transmiten una "idea preconcebida". En nuestra opinión, queda todavía por investigar el uso del texto aplicado a las imágenes en las noticias de televisión.

\section{Preguntas de investigación}

Por todo lo expuesto anteriormente nos plantemos las siguientes líneas de investigación:

1. Determinar un modus operandi en la redacción de las noticias en televisión con el fin de hacerlas comprensibles, más inteligibles y útiles en la vida de la ciudadanía que elige la televisión como medio para acceder al universo informativo.

2. Estudiar el lenguaje de la publicidad y su forma de narrar los mensajes, con objeto de aplicarla a la elaboración de noticias. Las técnicas publicitarias son eficaces en la transmisión de los mensajes audiovisuales, aunque muchos anuncios fracasen y resulte difícil cuantificar el impacto en las decisiones de compra o de elección de un producto por parte de los espectadores.

3. Identificar aquellos aspectos del lenguaje publicitario que se puedan trasladar a la redacción de noticias, pero sin caer en el error de identificarlas con el espectáculo o la persuasión.

4. Establecer un nexo en común entre la creación publicitaria y la producción periodística en los espacios informativos para evitar, tal y como aseguró McLuhan, que el medio sea el propio mensaje.

\section{Método}

Se ha estimado responder a las cuatro preguntas formuladas bajo una técnica de análisis comparativo en el que se han recopilado el corpus teórico de la creación publicitaria y de la narrativa periodística de televisión. Se han analizado diversos anuncios publicitarios, emitidos en los últimos años en las principales televisiones españolas y también anuncios que han sido premiados en diferentes festivales internacionales de publicidad. La redacción de los spots así como el ensamblaje con las imágenes utilizadas han sido comparadas con la articulación de las correspondientes noticias televisivas.

\section{Los campos compartidos del lenguaje publicitario y el lenguaje informativo}

Para analizar la publicidad como modelo de creación, la hemos entendido como un arte, además de como técnica, a pesar de que puedan surgir opiniones contrarias a la consideración de la creación publicitaria como creación artística. La publicidad crea, 
como crea todo artista, según apunta Magariños de Morentín (1984: 30), aunque los profesionales de este ámbito no se denominen artistas sino "creativos". En la elaboración de noticias, el proceso creativo no va ligado al momento de recabar la información, porque el periodista no "crea" la realidad sino que la reconstruye, la representa, la "recrea". El acto creativo intervendría en la reconstrucción de dichos hechos, en la manera de narrar y de exponerlos, conforme a unos criterios propios y en función del método objetivo imprescindible para elaborar cualquier información periodística [2].

Somos conscientes de que utilizar la creación publicitaria como modelo para la creación periodística en televisión puede convertirse en una estrategia peligrosa. Sobre todo, teniendo en cuenta que no existen estudios rigurosos que demuestren la eficacia de los anuncios publicitarios. Según recoge Ramonet (2000: 68), "nueve anuncios de cada diez pasan inadvertidos y cuatro marcas nuevas de cada cinco fracasan en su tentativa de imponerse al público, desapareciendo tan bruscamente como nacieron". Pero los anuncios también aportan información de una manera atractiva y aunque su eficacia, de cara a conseguir los objetivos, sea muy variable, sí existen abundantes estudios realizados por las propias empresas anunciadoras sobre los resultados de sus campañas publicitarias. Sirvan como ejemplo los magníficos resultados del producto "Cola-Cao" que, después de la campaña de publicidad elaborada por Duplo en 1987, pasó a liderar el mercado con un $60 \%$ de participación. O el caso del detergente "Wipp Express", que lo lideró durante dos años consecutivos tras la campaña de publicidad iniciada en febrero de 1989, o el de "Sanex", el gel de baño que desbancó a "Fa", a la sazón líder del mercado, con un $6 \%$ de participación, mientras que "Sanex" consiguió el $17 \%$ en 1989, tal y como recoge Soler (1997: 102-107). Y en la década que hemos dejado, ¿quién no se acuerda de las campañas de verano de la ONCE o el "te gusta conducir" de BMW?

Estos ejemplos son una muestra de que la técnica publicitaria puede llegar a ser muy eficaz, aunque partimos de la base de que información y publicidad son dos conceptos aparentemente contrapuestos. En sus comienzos se entendió la publicidad, según afirma Ferrer (1997: 169), como un proceso "eminentemente informativo, sin excluir las exageraciones que son propias de su naturaleza y de su destino".

Pero son conceptos contrapuestos en su finalidad, ya que la publicidad persigue modificar una actitud en beneficio de la empresa o entidad que se publicita, mientras que la información carecería, en principio, de una finalidad orientada a cambiar hábitos o pensamientos. Además, algunos autores califican la publicidad como una gran mentira. Séguéla, en Adam y Bonhomme (1997: 276) por ejemplo, asegura que,

"a causa de su propia naturaleza, la publicidad no puede informar sin deformar. Está pagada para no decir más que lo bueno. En cuanto argumenta, miente por omisión, ya que calla todos los defectos. La publicidad informativa es la única publicidad engañosa".

La publicidad y la información comparten contenidos, datos y, en definitiva, hechos noticiables. La publicidad, como las noticias, películas, canciones o programas de 
televisión, se articula a través de los textos; es decir, artificios culturalmente estructurados, que pueden llegar a representar modelos de comportamiento social. Tal y como apuntan Budd, Craig y Steinman (1999: 85), "si sabemos cómo leerlos pueden llegar a darnos la información más útil sobre nuestra sociedad y su historia, así como sobre sus sujetos y significados más obvios". La publicidad (Gil, 1997: 7) es entendida como "una comunicación masiva cuya finalidad es transmitir información y/o incidir sobre las actitudes (creándolas, modificándolas o reforzándolas) para impulsar a los destinatarios de la misma a un comportamiento favorable a los intereses del anunciante". Mientras que, por otra parte, "la información es un proceso de análisis, valoración, interpretación y tratamiento de la realidad constituida por hechos, ideas y datos cuyo resultado puede ser transmitido o almacenado" (Cebrián Herreros, 1998: 39) Siguiendo a Ferrer (1997: 167), información y comunicación son dos conceptos distintos, si bien este último se entiende como "un conjunto de medios y sistemas no sólo para informar, sino para persuadir". Ramonet (2001) contrapone los dos términos y asegura que el concepto de información ha cambiado negativamente, debido al influjo de la televisión, ya que "el periodismo televisivo, estructurado como una ficción, no está hecho para informar sino para distraer" pero los medios escritos siguen la estela televisiva con tal de intentar adaptarse a los nuevos tiempos.

Los anunciantes y los publicitarios aseguran que la publicidad contiene información, aunque se estima que más del $60 \%$ de los anuncios venden seducción/persuasión y prescinden de cualquier criterio informativo.

No queremos pisar las arenas movedizas del espacio generado por este binomio. Acotando bien cada campo, pretendemos determinar el punto de partida para elaborar una técnica lo más completa posible con la que producir las noticias de cara a su emisión en televisión. Desde que McLuhan (1968) planteó que los anuncios son noticias que presentan la singularidad de ser siempre buenas noticias, "estaba adelantándose a designar esa función que hoy cubre la publicidad televisiva de anunciar la conformación definitiva de la realidad en función de unos cánones estereotipados", tal y como recoge Zunzunegui (1989: 203). Por tanto, se trataría de utilizar un modus operandi que supere los problemas que genera la separación entre imagen, sonido, palabra y grafismo. En el ámbito de la información, a pesar de que el periodismo televisivo emplea las mismas herramientas de trabajo que la publicidad, no obtiene el mismo resultado. En la mayoría de los casos, las imágenes no explican los hechos por sí solas, debido a su dificultad para transmitir información y a que el texto que las acompaña tampoco ofrece los datos suficientes para contextualizar aquello que el ojo ve.

Por otra parte, en el lenguaje de los informativos de televisión, además de la publicidad, también influyen notablemente el lenguaje cinematográfico y, más recientemente, el lenguaje de la videocreación y de los videoclips musicales. Respecto al lenguaje cinematográfico, para Stephens es el director de cine Eisenstein, con su película October, el que marca el inicio de lo que él llama "nuevo vídeo" (Stephens, 1998: 100), con un nuevo lenguaje subliminal basado en la inclusión de planos que el ojo humano no puede percibir. Posteriormente, será la cadena MTV la que cree, con un nuevo lenguaje visual, el formato del nuevo vídeo. Para Cebrián Herreros (1998: 290), la asociación de 
elementos que aparecen en los diferentes programas de la televisión hace que se interrelacionen espacios de entretenimiento con anuncios y con películas,

"así puede observarse cómo una música asociada por el telespectador a unos programas que alcanzaron cierto éxito, y que se recuerda por tal motivo, se utiliza como fondo musical de un anuncio, con lo cual se logra una mayor penetración y un recuerdo más duradero en el espectador"

\section{Técnicas del lenguaje publicitario aplicadas a las noticias}

Para mejorar la calidad en la percepción de la información utilizaremos algunas de las técnicas y elementos constitutivos del lenguaje de la publicidad, con el fin de conseguir lo que uno de los clásicos métodos de creación publicitaria pretende bajo el acrónimo AIDA, según Furones (1980: 18-19): captar la Atención; despertar el Interés por conocer; atrapar el Deseo por saber más y desencadenar la Acción pero no la de comprar el producto sino, en este caso, la acción de Argumentar, de generar criterios propios tras recibir el impacto informativo. Dejando el espectáculo para otro tipo de programas conseguiremos hacer del lenguaje periodístico-audiovisual la herramienta precisa para transmitir de la manera más eficaz posible el mensaje.

Esta técnica sería la más parecida a la de "la idea clave", Bandrés et al., (2000: 91) pero es independiente a la de los diferentes métodos para la construcción del relato narrativo: tanto la pirámide invertida, cuestionada ya desde hace tiempo, el modelo Top-Down (Woodall, 1983), la estructura narrativa clásica de planteamiento-nudo-desenlace, los relatos organizados propuestos por Meadow y Reeves (1989).

En el aspecto formal, el anuncio publicitario puede dividirse en tres partes:

a) Encabezamiento o titulares, con el objetivo de llamar la atención;

b) Cuerpo, en el que se exponen los argumentos persuasivos;

c) Rúbrica o cierre.

La cohesión textual se logra por medio de una red de relaciones sintácticas y semánticas: enlaces interoracionales, repeticiones, paralelismos y todo tipo de conexiones léxicas, semánticas y gramaticales, según Ferraz Martínez (1996: 37). Y esto mismo ocurre en las noticias. El esquema de elaboración basado en: la idea clave, el planteamiento y el desenlace, se puede corresponder con las tres fases expuestas.

Pero en publicidad no existen normas, criterios fijos en la elaboración de la publicidad, ni tampoco en la integración del texto en el cuerpo del anuncio. Hay spots en los que apenas se escucha o se lee alguna frase, mientras que otros, en cambio, son un auténtico discurso, como el anuncio de la empresa Telefónica, "que explicitaba en un tiempo extremadamente largo (y caro) inusual en televisión (el anuncio duraba dos minutos), la labor de comunicación que ha desempeñado y desempeñará dicha empresa. Por el contrario, en un anuncio de la marca de pantalones "Levi's", realizado por Michel Gondry, se exacerba la gran utilidad del bolsillo pequeño de dicha prenda de 
vestir, por medio de una historia en la que no se dice ni una palabra: consta únicamente de imagen y música y, al final del anuncio, aparece una pequeña leyenda impresa en la margen izquierda de la pantalla del televisor.

Uno de los métodos en la creación publicitaria que puede plantearse en la redacción de noticias es el planteado por Joannis (1990: 19). Denominado "Copy platform" consiste en tener en cuenta cuatro aspectos.

En primer lugar, plantea la necesidad de determinar el público objetivo al que va dirigido el producto. La similitud con la noticia consistiría en la necesidad de pensar también en el espectador al que va dirigida la información. No habría que afinar tanto como en la creación publicitaria, que realiza un pormenorizado estudio sobre las características del público al que va dirigido el producto (edad, sexo, nivel sociocultural, la actitud respecto al producto, así como la opinión de los competidores y las cualidades de los productos similares de la competencia) pero sí se puede reflexionar sobre los receptores de dicha información o receptores a quienes les podría interesar. Como señalan Shanahan y Morgan (1999: 150), el consumo televisivo, por su misma complejidad, no guarda esencialmente relación con las variables dependientes de cada espectador, tales como la educación, la cultura visual, las condiciones del entorno, la capacidad de recepción y otros factores relacionados entre sí En este sentido, Lembo (2000) distingue dos categorías básicas de espectadores. Por un lado, aquellos que perciben los discursos televisivos como una representación de acontecimientos plausibles, que guardan alguna relación con su experiencia real. Dichos discursos se ajustan a una narrativa y siguen cierto orden lógico. Por otro lado, se encuentran quienes captan las imágenes, con un significado que no se halla sujeto a un discurso codificado y no buscan vincularlas a una narrativa lógica, a un sentido predeterminado. Esta categoría es la que Lembo (2000: 213) califica como "consumidores de imágenes". El consumo masivo de imágenes se produce en un entorno de aumento de la oferta de canales, de fragmentación de la audiencia y de creciente diferenciación social. Además, la complejidad del lenguaje audiovisual queda patente, como postula Hartley (1999) en los variados "usos" que cada espectador adopta mientras ve la televisión. Sin embargo, para Livingstone (1998: 21 50) no existe un modelo de espectador ni pautas de recepción demasiado cuantificables. Esta autora establece distintas categorías de espectadores que se contraponen entre sí: activo, pasivo, interpretador, consumidor, ignorante y conocedor. Plantea, además, la necesidad de estudios empíricos más completos que profundicen en el comportamiento de las audiencias, con objeto de conocer cómo el espectador dota de sentido a lo que ve en la pantalla (Ibid.: 190-191) Por otro lado, para autores como Aguaded (1999) y Farrés (1994), entre otros se requiere un mayor esfuerzo por parte de las instituciones y de las personas cualificadas para incrementar la educación de los espectadores en el uso de los medios audiovisuales.

Siguiendo con el método de Joannis, el segundo paso es marcarse un objetivo a alcanzar, es decir, qué cambio se espera obtener en el público objetivo: cambio de notoriedad, de actitud, de imagen o de comportamiento, entre otros. En la noticia, esta segunda fase se circunscribe a la aportación de la clave para el entendimiento de unos hechos. Que el espectador conozca la esencia de dicha información, para que la pueda 
emplear sin temor a equivocarse y como base para poder ampliar la información por su cuenta, en el caso de que le interese.

En el tercer momento Joannis (Ibid.:19) propone plantearse "la satisfacción que se quiere comunicar, la promesa, lo que se va a encontrar en el producto". En las noticias pocas veces se trata de satisfacciones, si lo ocurrido es un suceso o hecho luctuoso. Pero en casi todas las informaciones se puede despertar en el espectador diferentes enfoques que sean de su interés. Hay que buscar este interés y comunicarlo.

Por último, Joannis asegura que debemos plantearnos las "limitaciones", las normas éticas; es decir, lo prohibido, lo que no se puede transgredir ya sea jurídico o moral. En la noticia este paso constituiría en la verificación de las fuentes, la comprobación de que dicha información sea justa, veraz y objetiva.

Schultz y Barnes (1994: 171) comienzan con esta frase todos los inicios de campañas publicitaria: "¿Qué puedo decir y cómo puedo decirlo, para que mi mensaje sea lo bastante importante como para que el consumidor me dé suficientemente su atención y su tiempo, con el fin de que entienda y reaccione a mi mensaje de venta?". Decir y saber cómo decirlo es el paso fundamental, también en la elaboración informativa.

El segundo elemento en la creación publicitaria tiene que ver con los móviles perseguidos por el publicista. Dispone de dos vías: la intelectual y la afectiva. Esta última se puede articular según Bremond, (Ibid: 79) citado por los mismos autores, en móviles hedónicos, éticos y prácticos" Tal y como afirma José Luis León (1989: 91):

"La capacidad de un mensaje para persuadir no reside solamente en el conjunto argumental, sino también en el orden con que se presenten las argumentaciones dentro de la exposición. El hecho de que un argumento se sitúe al principio, al final o en medio de la exposición, hará variar el efecto de convencimiento en los receptores".

Si lo que se persigue es mejorar la capacidad informativa, también se puede utilizar el orden de aparición de las noticias para potenciar su comprensibilidad por parte del público. Este autor afirma algo ya conocido y asimilado por todo el mundo: que "en realidad lo visual y lo verbal ejercen un poder combinado, es decir, el mayor efecto se obtiene cuando ambos elementos trabajan reforzándose mutuamente" (Ibid: 105). Esto, que ya resulta imprescindible a la hora de realizar una noticia, la mayoría de las veces no se tiene en cuenta por diversas razones: la premura en la elaboración de las informaciones, la falta de imágenes específicas y la ausencia de planificación, por diversos motivos, a la hora de plantear la grabación. Se produce, por tanto, una separación entre imagen y texto altamente dañina para la comprensión de la noticia. No se tiene en cuenta que "lo visual se almacena con mayor intensidad, y por tanto, es posible que sea mejor recordado y reconocido" (Ibid: 191) El mismo autor recoge una propuesta de Paivio (1978) en la que se recomienda ofrecer primero imágenes visuales, en segundo lugar palabras concretas y, por último, las palabras abstractas" (Ibid: 101). 
Respecto al posible interés de la audiencia que hay que tener en cuenta a la hora de elaborar una noticia, José Luis León habla en todo momento de persuasión, un concepto que significa, según la Real Academia Española, "aprehensión o juicio que se forma en virtud de un fundamento". Si se tiene en cuenta que persuadir significa "inducir, mover, obligar a alguien con razones a creer o hacer algo", aplicar estos conceptos al ámbito informativo podría ser perfectamente asumible y extrapolable a la elaboración de las noticias ya que, "cuando el interés inicial de la audiencia es bajo, la argumentación más fuerte, más interesante, puede desatar la atención si es colocada al principio del mensaje, (...) cuando el interés es alto conviene hacerlo de manera progresiva, situando los puntos más fuertes al final" (lbid: 93).

En toda comunicación hay una línea de interés, tal y como asegura Overstreet (1995). "Si cruzamos esa línea, el público nos seguirá, al menos durante un tiempo. Por tanto, debemos buscar el modo de atraer al espectador desde el arranque".

En el campo publicitario, la persuasión se persigue, según este autor, "por dos vías complementarias:

a) La implicación de los receptores, y

b) La exaltación y ponderación de los productos".

Consideramos que este modus operandi también puede utilizarse en las noticias, aunque el objetivo final no sea la persuasión sino la información. Este planteamiento pondría en entredicho la pirámide invertida en el desarrollo del texto de la noticia, pero no en el lead de la misma, ya que la mantendría. Un esquema que también valdría para las noticias "volcadas" por las propias televisiones en sus webs, noticias que deberían incorporar el hipertexto y que la mayoría no integra.

En el campo informativo, la implicación de los receptores se debe conseguir elaborando la información por el lado más próximo a la audiencia a la que va dirigida. La información debe extraer las consecuencias que puedan afectar al público objetivo, porque el periodista no debe pensar que la televisión y el resto de soportes audiovisuales son medios de comunicación de masas. Como afirma George Hills, (1987: 18) "en el acto de redactar, realizar y transmitir, el comunicador ha de dirigirse no a sus queridos oyentes 0 telespectadores, sino a un solo telespectador, o grupo familiar". Y esto es así porque un espectador tiende a tomar su propio contexto como marco de referencia al realizar cualquier tipo de análisis del mensaje. "Los esquemas perceptivos de su medio, muchas veces no coinciden con los que proponen las imágenes", tal y como afirman Aparici, Valdivia y García (1987: 58). Otro de los rasgos publicitarios que puede aplicarse a las noticias, según Sánchez Corral (1991: 87) es la:

"Rehabilitación de los valores sensoriales del lenguaje, a fin de transformar la palabra, el sintagma o la frase en objetos materiales perceptibles directamente por los sentidos. Recurrencias fonemáticas, homofonías, alteraciones o armonías acústicas, son técnicas de persuasión de las que se vale el discurso para dirigir al receptor hacia una lectura auditiva". 
Es decir, lo que en este campo de la información se denomina "sonido ambiente" dirigido o lo que es lo mismo, utilizar todo ruido identificable que pueda ayudar a fijar la atención del espectador.

\section{El uso del lenguaje audiovisual en los mensajes informativos}

En el primer estudio sobre el lenguaje de la televisión en España, elaborado por el profesor Cebrián Herreros (1978: 28), se puso de manifiesto que "la TV es primero lenguaje audiovisual y luego televisivo. Son dos ámbitos individualizables pero no separables, puesto que los dos van unidos". Sin embargo, no hay que olvidar, tal y como señala Joannis (Ibid: 26), que "en el conjunto de imágenes/palabras, el ojo lee primeramente las imágenes y, luego, los textos, para precisar y concretar el contenido de lo que el ojo acaba de ver". Con todo, el lenguaje audiovisual presenta unas características propias, que pueden adaptarse al formato en el que se emite, bien sea la televisión u otro tipo de pantallas, aunque siempre sin olvidar, como afirma Vilches (1988: 190), que "la imagen tiene la estructura de un texto autónomo".

\subsection{Planos, transiciones}

El plano es la unidad más pequeña con la que se puede recrear la realidad. También en la redacción de noticias se utiliza la tipología de los diferentes planos. Durante la grabación, el plano empezará al accionar el botón de grabación de la cámara y terminará cuando éste vuelva a ser apretado. En cambio, en la edición de la noticia, el plano puede no coincidir con el obtenido en la grabación, ya que puede ser seleccionado un fragmento del mismo en función del ritmo del montaje. En cualquier caso, deben guardar un orden lógico. Así, cada cambio de frase debe ir acompañado de un cambio de plano, al que es recomendable introducir un sonido ambiente de apenas dos segundos para conseguir que no decaiga la atención del espectador.

La imagen cuenta además, como apunta Feliu García (1984: 195), con tres características que la definen:

a) El grado de iconicidad, que es el nivel de realismo de la imagen en relación al objeto.

b) El grado de figuración, que representa una mayor o menor exactitud respecto a los modelos.

c) El grado de complejidad, que depende del nivel de abstracción de la imagen.

En todo caso, la abstracción debe tener en cuenta, tal y como se indica en el libro de estilo de Telemadrid (1993: 59), que "la pantalla no es una ventana desde la que se observa el mundo tal cual es. Lo que se ve en ella es la reproducción electrónica, bidimensional y, normalmente, a escala distinta de la realidad". 


\subsection{Integración del texto}

La integración del texto en una noticia debe ir siempre acompañada por unas imágenes específicas. La palabra debe eliminar lo abstracto para plasmar lo concreto, potenciar el análisis y establecer los parámetros necesarios para que el espectador mantenga viva la llama de la crítica. Una vez establecida la estructura de la noticia, insertados los testimonios de los protagonistas y elegidos los cebos e ideas clave para conseguir varios puntos de inflexión que sirvan como puntos de anclaje en la memoria del público, la imagen debe ser siempre una fiel aliada del texto y viceversa.

Primero se graban los elementos que pueden servir para ilustrar lo que se quiere decir. Conviene visualizar estas imágenes antes de escribir con el fin de buscar la inspiración necesaria con la que ajustar el texto a lo ya grabado. Después se redacta el texto definitivo y por último se "pegan" las imágenes al texto elaborado teniendo en cuenta que siempre debe apoyarse en dichas imágenes. Esto significa que en el montaje del vídeo cada plano debe ir en el lugar que lo indique el texto.

\subsection{Elipsis}

Esta figura retórica consiste en la supresión de palabras que carecen de significado pleno dentro de una frase, sin que ello afecte finalmente a la comprensión de la misma. Generalmente, son los tiempos verbales los que se suprimen, con objeto de conseguir una mayor agilidad en la comunicación. Esta figura se encuentra directamente relacionada con la economía del lenguaje. Eliminando palabras en el texto publicitario y periodístico, se obtiene una mayor inmediatez y rapidez a la hora de transmitir la información.

La elipsis afecta, en mayor o menor medida, a casi todos los textos publicitarios, a los de noticias y al lenguaje audiovisual en general, ya que, resulta imposible contar absolutamente todo, tanto de forma textual como en imágenes.

Por lo tanto, en el lenguaje audiovisual la elipsis se hace necesaria, al resultar imposible narrar visualmente todos los elementos constitutivos de la historia que se está relatando. La elipsis aparece al cambiar de planos, bien sea por corte (es decir, "pegando" un plano a otro, sin ningún tipo de transición), bien por encadenado (paso en el que se diluye la imagen anterior para dejar paso a otra nueva), bien por algún tipo de "cortinilla" (situación que se da cuando aparece una barra, un ondulamiento, un corte en la imagen, que empuja al plano anterior e introduce el nuevo), bien desenfocando una imagen gradualmente para dejar paso a otra nueva, o bien mediante el fundido a negro (consistente en dejar la pantalla en color negro). Cualquiera de estos efectos son producidos por la cámara o por la mesa de mezclas y la variedad puede ser casi infinita.

Generalmente los verbos y los artículos son los elementos más afectados en esta supresión intencionada, que busca conseguir una mayor efectividad del mensaje recortando la enunciación. Por ejemplo, el coche Golf 4 Motion, de la casa Volkswagen, 
es presentado con el eslogan "Máxima adherencia sobre cualquier superficie". Esta frase ofrece una mayor rotundidad, sin un verbo y artículo, como por ejemplo: "presenta una máxima adherencia", o "desarrolla una..."

Entre estos recursos de condensación, Ferraz Martínez (1996: 36) propone las oraciones de infinitivo independientes y las construcciones nominales. La función de las primeras consistiría en conseguir, con un tono sentencioso, "subrayar los rasgos esenciales del producto". Por ejemplo: "Sentir sobre su piel la persistente caricia de Agua Profunda. Aspirar profundamente su nueva fragancia, joven, viva..." En cuanto a las construcciones nominales, se persigue especificar, de entrada, las bondades 0 características propias del producto. Por ejemplo, "Burger King, el rey de las hamburguesas", o "Fibermaster, el primer somier con fibra de carbono". El mismo esquema de estos ejemplos se utiliza habitualmente en el comienzo de la elaboración de las noticias.

La elipsis sirve, igualmente, para "respetar la duración de la realidad", como afirma Aparici et al. (Ibid: 172-173). Ramonet (2000: 85), va más allá y asegura que este "carácter fundamentalmente elíptico de los spots viene dado por la abundancia de primeros planos y su brevedad" pero, en realidad, son las propias leyes de la narrativa audiovisual las encargadas de "recortar" los planos para evitar que los relatos no sean admisibles. Por ejemplo, en un anuncio de una marca de comida para gatos ("Cat Chow", realizado por la agencia Bassat y Ogilvy en 1998 con una duración de 25 segundos), la elipsis visual permite a los realizadores evitarse los enormes problemas que hubiera suscitado meter a uno de estos animales al agua. En el spot, se ve a una mujer que entra por el jardín de su casa, con bolsas de comida en las que se puede ver el "Cat Chow". Pero la señora da un traspiés y la caja aterriza en el agua. La elipsis hace que el siguiente plano sea, en lugar de la imagen del gato en la piscina, el de la señora secando al animal mientras dice: "De lo que eres capaz por tu Cat Chow". Texto e imagen se complementan para que se deduzcan las acciones anteriores y, de ese modo, no se note en absoluto la falta de dichos elementos visuales y auditivos (es decir, que no se note que en realidad, se ha producido un corte en la narración) pues, tal y como apunta Vilches (Ibid: 39), "interpretamos la imagen como un texto no escrito que ha de leerse".

En una noticia, la elipsis visual también se hace imprescindible ante la falta de imágenes específicas para cubrir el texto. Esta supresión de imágenes se reflejó en la cobertura informativa del atentado a las Torres Gemelas de Nueva York el 11 de septiembre de 2001, cuando se trataba de la recuperación de las víctimas atrapadas entre los escombros. Las televisiones norteamericanas se pusieron tácitamente de acuerdo para no grabar la evidencia más dolorosa del atentado, por respeto a esas víctimas y a sus familiares. Los comentaristas de todo el mundo siguieron informando de las labores de rescate, del número de muertos y de los desaparecidos, sin una sola imagen de las víctimas mortales.

La elipsis, por lo tanto, constituye un elemento imprescindible en la narración audiovisual porque permite continuar con el relato sin emplear todos los planos que, en pura lógica, 
serían necesarios. Posibilita saltar en el tiempo omitiendo planos pero no información, por lo que esta omisión lógica y deliberada no influye en el desarrollo del discurso audiovisual.

\subsection{Música}

La música constituye un elemento dramático importante en la edición de los reportajes televisivos, pero no en las noticias, ya que no suele utilizarse debido a su escasa duración. El tipo de música empleada dependerá del carácter del reportaje. Un suceso dramático, luctuoso o de gran impacto social exigirá una música cuya melodía manifieste sensaciones acordes con el contenido del asunto tratado. La música, como sucesión de sonidos, aporta al reportaje un complemento sensorial que ayuda a que la narrativa tanto visual como textual y sonora se manifiesten de manera mucho más armónica. $Y$ a ello contribuye el lenguaje propio del que se sirve esta disciplina para materializar un tipo de expresión que apela directamente a los sentidos.

La música consigue también fijar la atención del espectador debido a que es el sonido lo primero que reclama su atención pero, además, "interpreta las imágenes sin describir con redundancia la acción que ocurre en la pantalla", tal y como afirma Scott (1979: 203), de tal manera que la imagen se apoya en la música a la hora de insertarse en la narración audiovisual; es decir, en el momento de editar un reportaje, primero se insertará el texto, luego la música y finalmente la imagen. Sin embargo, muchas veces por razones de tiempo lo último que se inserta en un reportaje ya editado, es la música.

\section{Conclusiones}

Por todo lo anteriormente expuesto, creemos que las técnicas de redacción del lenguaje publicitario pueden utilizarse como recurso en la redacción y edición de noticias audiovisuales. Consideramos que debe ser una herramienta útil, práctica y habitual en las redacciones de televisión. Salvando todas las distancias existentes entre los dos campos, su utilización en la elaboración de noticias podría mejorar notablemente el lenguaje informativo, tanto en la exposición del mensaje como en su comprensión por parte del espectador.

Hemos pretendido plantear una serie de herramientas para mejorar el lenguaje de las noticias de televisión de la manera más efectiva posible, con el fin de generar más comprensión, análisis, recuerdo y una mayor capacidad de respuesta en el público receptor. Teniendo en cuenta cómo se lleva a cabo la percepción de las noticias televisivas por parte de la audiencia, sugerimos a quienes desempeñan esta profesión en el medio televisivo que tengan en cuenta estos parámetros en los que basarse para elaborar su trabajo. 


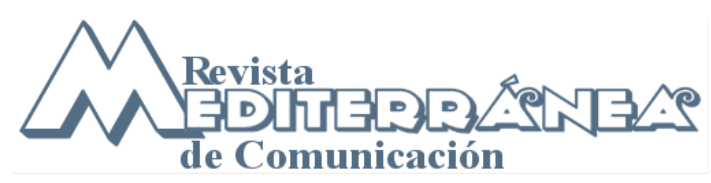

ISSN 1989-872X - Año 1(2010), pp. 173-194

\section{Referencias bibliográficas.}

Aguaded, J. I., (1999): Convivir con la televisión. Familia, educación y recepción televisiva. Barcelona: Paidós.

Aparici, R., Valdivia, M., y Garcia Matilla, A., (1987): La imagen. Iniciación a la lectura de la imagen y al conocimiento de los medios audiovisuales, Vol. I y Vol. II, Madrid: UNED.

Bandrés, E., Pérez, Gabriel., y otros, (2000): El periodismo en la televisión digital, Barcelona, Paidós.

Bourdieu, P., (1997): Sobre la televisión, Barcelona: Anagrama.

Budd, M., Craig, S., Steinman, C., (1999): Consuming Environments, and Comercial Culture, Nueva Jersey: Rutgers University Press.

Cebrián Herreros, M., (1978): Introducción al lenguaje de la televisión,

Madrid,:Ediciones Pirámide.

Cebrián Herreros, M., (1998): Información televisiva. Contenidos, expresión y programación, Madrid: Síntesis.

Cortés, J.A., (1999): La Estrategia de la seducción, Pamplona: Eunsa.

Del Rey Morató, J. (1998): El naufragio del periodismo en la era de la televisión. La industria del infoentretenimiento: de Aristóteles a Walt Disney, Madrid: Editorial Fragua.

Diazhandino, M.P., (1994): El quehacer informativo, Bilbao: Universidad del País Vasco.

Eguizábal, R., (1999): Historia de la publicidad, Madrid: Eresma.

Farrés, J., (1994): Televisión y educación, Barcelona: Paidós.

Feliu García, E., 1984: Los lenguajes de la publicidad, Alicante: Universidad de Alicante.

Ferraz Martínez, A., (1996): El lenguaje de la publicidad, Madrid: Arco Libros.

Ferrer, E., (1997): Información y Comunicación, México, Fondo de Cultura Económica.

Fombona Cadavieco, J., (1997): Pedagogía integral de la información audiovisual, Universidad de Oviedo, Gijón: Ayuntamiento de Gijón.

Furones, M. Á., (1980): El mundo de la publicidad. Barcelona: Aula Abierta Salvat.

Gil, A., (1993): Color, Imagen y Lenguaje de la Publicidad, Zaragoza: Gobierno de Aragón.

Gonzalez Requena, J., (1989): El espectáculo informativo, Madrid: Akal Comunicación.

Hartley, J., (1999): Uses of television, Londres: Routledge.

Hills, G., (1987): Los informativos en Radiotelevisión, Madrid: IORTV

Joannis, H., (1990): El proceso de creación publicitaria, Bilbao: Ediciones Deusto.

Lembo, R., (2000): Thinking through Television, Cambridge, Cambridge University Press.

León, J.L., (1996): Los efectos de la publicidad, Barcelona: Ariel.

Libro de estilo de Telemadrid, 1993: Madrid: Ediciones Telemadrid.

Livingstone, S., (1998): Making Sense of Television. The Psychology of Audience Interpretation, $2^{\mathrm{a}}$ ed., Londres: Routledge.

López Eire, A., (1998): La retórica en publicidad, Cuadernos de lengua española, Madrid, ArcoLibro.

Magariños de Morentin, J. A., (1984): El lenguaje publicitario, Buenos Aires: Librería Hachette. 
Mcluhan, M., (1972): La comprensión de los medios como las extensiones del hombre, México: Ed. Diana.

Orive Riva, P., (1988):Los españoles ante los telediarios, Madrid: Asociación de Estudios de Comunicación.

Postman, N., (1991): Divertirse hasta morir. El discurso público en la era del "show bussines", Badalona: Editorial de la Tempestad.

Ramonet, I., (2000): La golosina visual, Madrid: Ed. Debate.

Sánchez Corral, L., (1991): Retórica y sintaxis de la publicidad, Córdoba, Universidad de Córdoba.

Sartori, G., (1998): Homo Videns. La sociedad teledirigida, Madrid, Taurus.

Schultz, D. E. y Barnes, B. E., (1994): Strategic advertising campaigns, Illinois: NTC Business Books.

Scott, J.F., (1979): El cine, un arte compartido, Pamplona: Eunsa.

Shanahan, J., y Morgan, M., (1999): Television and its Viewers, Cambridge: Cambridge University Press,.

Soler, P., (1997): Estrategia de comunicación en publicidad y relaciones públicas, Barcelona, Gestión 2000.

Stephens, M., (1998): The rise of the image. The Fall of the World, Nueva York : Oxford University Press.

Vázquez, I., Aldea, S., (1991): Estrategia y manipulación del lenguaje, Zaragoza: Universidad de Zaragoza.

Vilches, L., (1988): La lectura de la imagen, Barcelona: Paidós Comunicación.

Zillman, D., y Vorderer, P., (2000): Media Entertainment. The Psychology of its Appeal, Nueva Jersey: Laurance Erlbaum.

Zunzunegui, S., (1989): Pensar la imagen, Cátedra, Madrid: Universidad del País Vasco.

\section{0.- Referencias en la red}

Anuario de audiencia de TV en 2008. Disponible en: http://www.tns-global.es/areasexpertise/audiencia-de-tv/anuario-de-audiencia-de-tv-2008/

Asociación de la Prensa de Madrid. Informe Anual de la Profesión Periodística 2009.

Asociación para la investigación de los medios de comunicación (AIMC), Estudios General de Medios. Febrero a Noviembre de 2009. Disponible en: http://www.aimc.es/aimc.php?izq=egm.swf\&pag html=si\&op=cuatro\&dch=02egm/24.htm $\underline{1}$

Barómetro de Opinión de octubre de 2003. Disponible en: http://www.cis.es/cis/opencms/-Archivos/Marginales/2540_2559/2541/Es2541.pdf

Estudio sobre los informativos de televisión generalistas en España. Universidad de Navarra, Universidad Complutense de Madrid y Universidad Pompeu Fabra de Barcelona, 2006. Disponible en: http://www.unav.es/fcom/noticias/docsnot/0602EstudioTV.pdf 
European Interactive Advertising Association. Internet ya rivaliza con la televisión en consumo de medios. Disponible en: http://www.eiaa.net/news/eiaa-articlesdetails. . asp? $i d=155 \&$ lang $=5$

Estudio General de Medios, octubre de 2000 a mayo de 2001. Disponible en: http://www.aimc.es/aimc.php?izq=egm.swf\&pag $h t m l=s i \& o p=c u a t r o \& d c h=02 e g m / 24 . h t m l$

EGM de octubre de 2008 a mayo de 2009. Disponible en:

http://www.aimc.es/aimc.php?izq=egm.swf\&pag html=si\&op=cuatro\&dch=02egm/24.html

Centro de Investigaciones Sociológicas, Barómetro de julio de 2000. Disponible en: http://www.cis.es/cis/opencms/Archivos/Marginales/2380_2399/es2396.pdf

Martínez Albertos, J.L., El periodismo en el siglo XXI: Más allá del rumor y por encima del caos. Revista: Estudios sobre el mensaje periodístico. Recuperado el 21 de noviembre de 2009.: http://www.ucm.es/info/emp/Numer 05/5-3-Estu/5-3-1.htm.

Ramonet, Ignacio. Información contra Comunicación, en Sala de Prensa, Abril 2001, Año III, Vol. 2. Disponible en: http://www.saladeprensa.org/art210.htm

Pestano Rodríguez, José (2008): "Tendencias actuales en la estructura y contenidos de los informativos de televisión", publicado en Revista Latina de Comunicación Social, 63, páginas 453 a 462. La Laguna (Tenerife): Universidad de La Laguna.

http://www.revistalatinacs.org/08/38 $79560 \mathrm{TV} /$ Jose Pestano Rodriguez.html

DOI: $10.4185 /$ RLCS-63-2008-795-453-462

Sánchez Corral, L., 2003: De la crisis de la significación o las palabras pervertidas. Lección Magistral. Universidad de Córdoba. Recuperado el 3 de enero de 2008. http://www.gestion.uco.es/gestion/comunica/prensa/informacion/memoria/2003/memoria/1 $\underline{\text { 2.htm }}$

\section{Notas}

[1] En 1928 Charles F. Jenkins, desde la estación experimental W3XK de Washington, inicia las primeras transmisiones experimentales con una definición de 48 líneas. Logie Baird transmite imágenes de Londres a Nueva York. En España, será el 28 de octubre de 1956 cuando comiencen en las instalaciones de TVE en el Paseo de la Habana de Madrid, inauguradas ese día, los primeros programas regulares de TV que llegan a toda el área de la ciudad. La programación duró dos horas y consistió en una documental sobre El Greco y unos bailes regionales de la Sección Femenina. Eguizábal, R., Historia de la publicidad, Eresma, Madrid, 1999, p., 484

[2] Sabiendo que en este asunto nos introducimos en el controvertido asunto de la objetividad periodística, colateral por otra parte al tema que aquí nos ocupa, sirva como 
sucinto apunte nuestra opinión de que la objetividad periodística como tal no existe pero sí un método objetivo con el que se debe elaborar las noticias. 